\title{
Chapter 8 \\ Understanding the Mechanisms \\ of Intergenerational Social Inequality \\ in Demographic Behavior
}

Nicole Hiekel

\subsection{Introduction}

The way in which family background contributes to social inequality is a key social science question. A central goal of the CONOPP project is to advance our understanding of the role of demographic events and trajectories in producing and reproducing social inequality across generations. It is empirically evident that young adults from advantaged family backgrounds make committal and irreversible life transitions in the family and partnership sphere later and in more stable relationship contexts than the disadvantaged (Billari et al. 2019). At the theoretical core of this research strand are economic and cultural transmission models of social inequality. These models are based on assumptions about various social mechanisms that explain why and how parents and the family context during childhood shape their children's life courses through adulthood.

\subsection{Economic and Cultural Perspectives on Intergenerational Transmission Processes of Social Inequality}

Intergenerational transmission processes from parents to their children are grasped from an economic perspective on the one hand, and from a cultural perspective on the other. Both start from the assumption that parents with high socio-economic status (SES) differ systematically from low-SES parents both in preferences and

\footnotetext{
N. Hiekel $(\bowtie)$

University of Cologne, Cologne, Germany

e-mail: hiekel@wiso.uni-koeln.de
} 
behavioral investments that guide their efforts to positively influence their children's opportunities in life. Central is thus the assumption that parents of high and low SES differ in their parental resources that determine their parenting behavior and ultimately impact their children's young adult demographic behaviors. This would result in socially stratified patterns of demographic outcomes and intergenerational similarities (e.g. McLanahan and Percheski 2008).

\subsubsection{The Economic Perspective}

The economic perspective focuses on poverty as a dynamic process constraining people's quality of life (Atkinson 1998) resulting from a combination of lack of capabilities required to participate in social life (e.g., poor skills, labor market exclusion, poor housing), various forms of exclusion from social, political and cultural life, and the insufficiency of different attributes of wellbeing (e.g., health, income).

Economic approaches, such as the neoclassical human capital approach (Becker 1964; Mincer 1974), focus on the transmission of socio-economic status in predicting young adults' educational investments and achievements that, in turn, are linked to their demographic choices in young adulthood and, jointly, to socio-economic outcomes later in life. In the economic view, parents invest in human capital of their children that affect their earning potential, income, and also, their success on the marriage market. According to the family resource model, the economic status of parents is transmitted to children via other pathways than the (lack of) economic resources, namely characteristics of the parents that correlate with SES, such as diligence, determination, good health, and willingness to co-operate that, if transmitted from parents to children increases their life chances more than money can (Mayer 1997). As a result, young adults from different socio-economic backgrounds are expected to differ in investments into higher education, that in turn are linked to the timing of committal and irreversible life transitions in the family and partnership sphere. The influence of family background extends beyond the simple intergenerational transmission of human capital. Rather, the cumulative advantage perspective (Crystal and Shea 1990) suggests that advantages (and disadvantages) during childhood and early adulthood continue to accumulate. This implies that initial differences between children from high and low SES backgrounds grow larger over time. The greater human capital that children from advantaged family backgrounds possess and supports them in attaining higher educational degrees also helps them in attaining higher-status occupations. Moreover, their affluent parental background both in terms of money and social influence, serves as a safety net to overcome obstacles in acquiring and maintaining a high socio-economic status later in life. 


\subsubsection{The Cultural Perspective}

The cultural perspective focuses on learning processes and other forms of social interaction across and within generations. From this perspective, the socio-economic stratification of young adults' demographic behavior is explained by the transmission of values from parents to children and their link to demographic choices in young adulthood. As part of their socialization efforts, parents transmit values to their children that refer to specific desirable (life) goals and serve as standards or criteria in guiding young adults (demographic) behavior (Barber 2000). Both purposeful and indirect socialization modes of transmission processes are distinguished (Cavalli-Sforza and Feldman 1981). Purposeful socialization refers to conscious efforts to influence the child guided by so-called paternalistic empathy. Religious parents, for instance, may transmit their beliefs via rituals to their children, for instance by integrating religious practices in their family life, such as praying and visiting religious services. In a partially conscious and partially unconscious learning process, termed enculturation, children adopt or imitate their parents' ways of thinking and believing. Parental convictions about what is best for their child also guide their parenting styles as well as the extent to which they provide or constrain opportunities to their children to engage in behavior that is (not) congruent with their beliefs. Parents, however, also influence their children in less purposeful ways, referred to as social learning (Bandura 1977). Parents who divorce may illustrate to their child an available course of action to end an unhappy relationship.

Parents of high and low SES may differ in the socialization goals they have which in turn will contribute to a social stratification of plans and expectations that their children will develop as regards the timing and context of demographic events in the partnership and family sphere (Keijer et al. 2016). Billari et al. (2019) showed that an advantaged family background on the one hand supports adult children in realizing planned events in the partnership and family trajectory, such as union formation, marriage and parenthood and on the other hand provides greater opportunities to postpone demographic events that - if experienced too early - may hamper upward social mobility.

\subsection{Childhood (Dis)Advantage and Young Adult Demographic Behavior}

CONOPP studies the intergenerational reproduction of social inequality via the timing and context of demographic choices that are known to have potential adverse social and economic consequences. In the following, I will provide a compilation of economically and culturally framed social mechanisms that are scattered across the inequality literature and predict intergenerational linkages between socio-economic status of the family of origin and partnership and family behavior of adult children. 
I will discuss empirical evidence of these mechanisms based on the CONOPP studies.

The educational level of successive generations within a family is remarkably similar. The intergenerational transmission of education has been identified as an important social mechanism explaining the social stratification of demographic behavior. Educational (status) attainment is often viewed as a prerequisite of experiencing demographic markers of the transition to adulthood. Young adults who are enrolled in education are not considered "at risk" of making committal life decisions, such as marriage and parenthood because of the often implied economic dependence on their parents on the one hand and normative views on role (in)compatibility on the other (Blossfeld and Huinink 1991). Indeed, CONOPP studies provide empirical evidence for a greater postponement of such demographic life course markers (i.e. union formation, marriage, childbearing) among more advantaged children (Billari et al. 2019). An economic explanation would thus be that their parents possess greater opportunities to afford their children's investment in education for longer periods of their life. As a result, they are enabled to attain higher economic status. Children from low-SES family background by contrast may be pushed towards economic independence earlier in their life at the cost of attaining lower economic status.

Education is also - if not predominantly - conceptualized as a form of cultural capital, hence a non-monetary social asset. As a central indicator of life chances, education is transmitted from parents to children in the form of educational aspirations on the one hand, and via educational abilities on the other. The socialization of educational aspirations and abilities in the family is to a large extent purposeful, that means, parents devote various forms of resources to influence their children's educational preferences as well as the cultural and cognitive traits to reach their educational goals. For instance, parents of high and low SES differ in the amount of time they read to their children (Cano 2019; Guryan et al. 2008; Ramey and Ramey 2009; Hofferth and Sandberg 2001), the type and amount of extra-curricular activities their children attend (Weininger et al. 2015) and the schools they send their children to and where certain norms of behaviors and attitudes are cultivated (Khan 2011; Lareau 2003). Access to books, computers and other study material like newspapers and a quiet working space as part of the parental home's equipment create greater opportunities to engage in educational activities outside compulsory schooling for the more advantaged. Higher-SES parents tend to engage their children in concerted cultivation (Lareau 2003) marked by parents' conscious efforts to promote their children's talents, language use and social interaction in structured environments, thus promoting their children's cultural habitus. Lower-SES parents tend to engage their children in the "accomplishment of natural growth" in which children fill unstructured time with activities to occupy themselves, and receive less support in preparing for highly structured social environments, such as schools and universities.

But it is not only aspirations and abilities that explain the social gradient in the access to higher education that in turn is associated with demographic choices in young adulthood. Parents of high socio-economic status exert social closure 
behavior in order to monopolize their offspring's access to the scare resource of (high) education. Such opportunity hoarding (Tilly 1998) can take various forms. Higher-SES parents use their greater power in society by facilitating their children's access to formal and informal networks and other modes of cooperation opening gateways to higher education. Their descendants in turn profit from an educational system that is attuned to the cultural codes that are dominant among high-SES social groups (Bourdieu 1977). In his seminal work, French sociologist Pierre Bourdieu proposed that the cultural capital transmission runs via social mechanisms of distinction, hence social class-immanent cultural and linguistic codes, with the consequence that class-based social groups are reproduced across generations (Bourdieu 2010). Children would internalize the preferences and behaviors established in their social class of origin early in their lives and behave accordingly. This line of thinking may be transferred to the behavioral attitudes in partnership and family formation and their observed social stratification.

Two CONOPP studies (Billari et al. 2019; Keijer et al. 2016) specifically looked into the mechanisms of intergenerational transmission of preferences regarding family life transitions. Keijer et al. (2016) found that parents' cultural status (measured by their educational level) and to some extent their economic status (measured by income) influenced their children's preferences regarding the timing of first marriage and entry into parenthood. Children of parents with high socioeconomic status preferred to experience these events later than their peers from low-SES background. Billari et al. (2019) combined parents' educational and occupational status in a SES background measure and investigated the intentions of young adults aged 18-35 to experience different demographic milestones in the next 3 years. They also found that high-SES young adults intend to postpone to start living with a partner, marrying and entering parenthood.

These studies did not test the underlying social mechanisms directly. However, by including the adult child's own socio-economic status (often measured by highest level of educational attainment) in a model that links parental background to demographic behavior in young adulthood, nearly every CONOPP study provided evidence in favor of the education transmission process (Brons et al. 2017; Koops et al. 2017; Mooyaart and Liefbroer 2016). Though the importance of this social mechanism seems to vary by outcome variable studied (or data or method used to analyze the link), the effects of parental SES were significantly reduced and sometimes disappeared when own education was accounted for. This suggests that young adult's own education is an important mediating factor in the reproduction of social inequality in the demographic domain.

It is a prominent belief but rarely explicitly examined that norms, attitudes and values impact demographic behavior (Liefbroer and Billari 2010) but if so, attitudes have been shown to differ across social groups (Surkyn and Lesthaeghe 2004). Obviously, the transmission of norms and values and their links to demographic behavior may thus constitute a complementary pathway explaining that more educated young adults make different choices in the timing and context of committal and irreversible life transitions. 
The internalization of parental norms by their children is at the core of cultural transmission models that make a number of assumptions about conformity, resistance and authority in parent-child social interactions that are discussed in detail in a review by Grusec and Kuczynski (1997). The basic notion is that children's demographic choices in young adulthood are the result of compliance with parental socialization efforts that consist of explicit reward and punishment on the one hand, and subtle indications of approval or disapproval on the other (Patterson et al. 1992).

Social norms as "the grammar to frame the writing of our lives and interactions" (Gavac et al. 2017, p. 333) differ across social groups. Kohn (1969) found greater appraisal of self-direction among high-SES groups and of conformity among lowSES groups. SES differences also exist in the opportunities of parents to enforce their norms upon their children. Low-SES parents are limited in their capacities to outsource household and care tasks which in turn limits their opportunities to spend quality time with their children as well as to monitor their children's actions. In addition, unfavorable housing conditions may push their children to spend more time outside the immediate surveillance of their parents (Baizán et al. 2014). These considerations may explain why parental styles are socially stratified with authoritarian and uninvolved parenting styles being more prevalent in low-SES groups and authoritative and permissive parenting styles being more prevalent in high-SES families (Baumrind 1967).

Social norms are strong predictors of behavior (Kallgren et al. 2000). Regarding their children's demographic choices in young adulthood, parents who value personal autonomy to a greater extent make efforts to influence their children in such ways that they (prefer to) become independent by leaving the parental home earlier and make commitments to partnership and family formation later in their life. Indeed, the finding that children from high-SES family backgrounds do not only prefer but actually also succeed in making partnership and family transitions later in life is one of the most consistent findings in CONOPP that cannot be explained by transmission of education alone (Brons et al. 2017; Koops et al. 2017; Keijer et al. 2016; Mooyaart and Liefbroer 2016). One could also expect that high-SES parents are more open towards their children choosing alternative living arrangements to the institution of marriage for making these transitions, since unmarried cohabitation as part of secularization and individualization processes that modern societies are undergoing, emerged among the higher, rather than the lower educated. Indeed, Brons et al. (2017) found evidence that cultural transmission processes may explain that young adults from high-SES backgrounds tend to favor premarital cohabitation over direct marriage. However, high-SES families clearly tend to disfavor cohabitation as a childbearing context - with the exception of a small number of countries where cohabitation is widely diffused and enjoys social and legal acceptance (Koops et al. 2020).

Cultural models of transmission also incorporate the notion of stratified resources that were central to economic transmission models discussed earlier. Parents of different socio-economic status differ in their capabilities to exert life course agency (Hitlin and Elder 2006), implying the competence to pursue life plans effectively and with perseverance (Clausen 1991). This mechanism was explicitly tested in one 
CONOPP study by Billari et al. (2019). They showed that children with high-SES family background were more likely to realize their intentions regarding important demographic milestones in young adulthood, compared to their peers with low SES. With the exception of first birth, this study shows that young adults from different socio-economic background are not equally able to act in accordance with their intentions and thus, exert life course agency.

Social mechanisms of parental empathy and parent's abilities to transmit values that they consider best for their child reach their explanatory limits when we try to make sense of the observation that children from low socioeconomic background are more likely to engage in "risky" demographic behavior, that is likely neither reflecting their own nor their parents' preferences, such as unprotected sexual intercourse, teenage childbearing or poor assortative matching. The closest we may come to explaining such intergenerational regularities in life events and trajectories is to apply social learning theory (Bandura 1977): It implies cognitive mechanisms that refer to unintended transmission processes, namely children consciously or unconsciously imitating their parents' (lack of) capabilities as well as behavior. Social (or observational) learning processes are viewed as cognitive processes taking place in social contexts in which individuals observe and finally imitate existing norms and behaviors in the absence of direct reinforcement.

\subsection{The Long Arm of Childhood (Dis)Advantage}

Empirical research has confirmed that partnership and family behavior run through generations of families. Social scientists have postulated that intergenerational transmission processes of demographic behavior contribute to the reinforcement of socio-economic (dis)advantage (McLanahan 2004; McLanahan and Percheski 2008). The life course perspective of the CONOPP project permits the identification of later life consequences of childhood disadvantage via demographic behaviors in young adulthood.

In line with the life course analytical concept of path dependency, childhood family structure and opportunities can trigger a self-perpetuating process by which childhood disadvantage amplifies over the adult life course. As regards partnership and family formation choices, processes of path dependency refer to the constraints that some of these demographic events imply for (further) educational and occupational investments. It is noteworthy that these relationships are highly gendered due to women's traditional greater obligations in foregoing career for unpaid care labor within the family. Gender thus adds another layer of social inequality here.

In particular one CONOPP study illustrates the implications of union formation and dissolution for the stratified opportunities (and constraints) of women with and without children to profit from economics of scale and attachment to the labor market until later in life (Muller et al. 2020). They investigated the earnings gradient of women with different family and partnership trajectories in 22 European countries. Findings showed that the absence of a partner implies a greater need to commit to 
labor market activities that generate - above all - sufficient income and are compatible with potential care duties for existing children. Beyond their childrearing years, women aged 50 and over who had followed traditional family trajectories (i.e. the traditional housewife-breadwinner model) had the lowest earnings of all women which implies a persistent personal disadvantage in terms of economic independence from their partner. Women who neither committed to a partner nor a family had the highest earnings at advanced stages of their work career. Women who did not profit from economies of scale due to an absent partner or who had a care burden during mid-age occupied earnings positions in between these extremes.

As regards the socio-psychological consequences of socially stratified demographic behavior, the literature distinguishes two types of life course script deviations with potential disadvantageous consequences in the spheres of wellbeing and social support. Life course script deviations contribute to the intergenerational reproduction of social inequality if low-SES young adults disproportionally often experience them. Demographic life course markers may, on the one hand, be forgone altogether, and, on the other hand be experienced off-time. The latter implies experiencing events such as union formation, marriage and parenthood much earlier or much later than social norms convey. Life course script deviations often provoke social stigmatization and a lack of social support and in turn, may decrease wellbeing, both economically and socially.

These psychosocial mechanisms were addressed by Zoutewelle-Terovan and Liefbroer (2018) who focused on the relationships between family trajectories and later life loneliness. They found that lifelong singlehood and childlessness were associated with greater feelings of loneliness later in life. While they found no evidence for effects of early transitions, experiencing demographic milestone events later than socially expected increased risk of loneliness as well.

Another health-related outcome of family trajectories was investigated by Mooyaart and Liefbroer (2018) who showed that parenthood had health consequences via dietary changes and changes in physical activity, that jointly affect the risk of obesity. In their study, traditional family trajectories (male breadwinner, female housewife) most strongly punished men and women in terms of BMI. The explanation may be that a gender-specific specialization in paid and unpaid work and little outsourcing of care and household tasks increases stress and limits opportunities to self-care. Part of the explanation may also be that a traditional division of tasks no longer is the socially expected way of contemporary family organization.

\subsection{Cross-National Variation in the Transmission of Social Inequality}

A key question addressed in the CONOPP project is the extent to which the relationships between childhood (dis)advantage, young adult demographic choices and later life outcomes vary by national contexts of opportunity. Two aspects of the 
national context were investigated as potential moderators of these relationships: (1) economic aspects, such as income inequality, intergenerational social mobility (Mooyaart and Liefbroer 2016; Studer et al. 2018), and female labor force participation and earnings (Muller et al. 2020) and (2) cultural aspects, such as family related norms and behaviors (Brons and Härkönen 2018; Brons et al. 2017; Koops et al. 2017; Mooyaart and Liefbroer 2016; Zoutewelle-Terovan and Liefbroer 2018).

The importance of parental monetary resources for children's status attainment can be expected to be greater the more an institutional framework, such as the educational system, is distorted in favor of the powerful. High admission fees for college, extracurricular (paid) activities to pass prep classes, unpaid internships, access to networks and other modes of cooperation are usually more accessible (feasible) for children from more affluent social strata. Keijer and co-authors (2016) found strong evidence for the educational transmission of educational opportunity in the Netherlands, a country with a highly stratified educational system. Studying the United States, a country that likes to think of itself as the very embodiment of meritocracy, Mooyaart et al. (2019) found that career (and family building) decisions during young adulthood only partially explained income trajectories during later adulthood. Family background continues to play a significant role in explaining income differentials in adult life courses and operates beyond the mere transmission of SES. Rather, these findings suggest cumulative advantage to be at play that is particularly pronounced in societies with little institutional effort in equalizing socio-economic inequality by birth.

The transmission of values via socialization and social learning processes is expected to be weaker in countries where individualization and related societal change is more advanced. First, this is because parents in more individualized societies may stronger encourage personal autonomy of their children and thus aim at imposing less of their personal values and attitudes about family life as part of their socialization efforts and their children may be more resilient to take over readymade life scripts from their parents. Second, non-traditional living arrangements are more strongly diffused through society, and thus less concentrated among either the high- or low-SES social groups and thus more accepted by both high- and low-SES parents.

The CONOPP project could not test these mechanisms directly, not least because data on young adult family-life courses in the surveys used were collected retrospectively and parental preferences (during early years of childrearing) were not measured. However, they consistently find that the strength of the association between family background and demographic choices during adulthood and, eventually, related outcomes are weaker in countries where divorce rates are higher (Brons and Härkönen 2018), and where demographic behavior associated with the Second Demographic Transition is more diffused (Brons et al. 2017; Koops et al. 2017; Zoutewelle-Terovan and Liefbroer 2018).

Finally, parental transmission processes are expected to be less important in societies were institutions buffer the negative consequences of childhood disadvantage. Educational systems that permit upward mobility may weaken the transmission of education particularly in disadvantaged families. Societies that are 
more defamilialized, thus allowing parents (and particularly women) to combine career opportunities and family responsibilities in favor of higher integration in the labor market are expected to make later-life economic status less contingent on demographic choices in the family sphere. Indeed, Muller and co-authors (2020) found that the earnings gradient between women with different care burden during the childrearing years was smaller in societies where female labor force participation was higher.

\subsection{Some Suggestions for Future Research}

The CONOPP project was successful in realizing one of its key aims, namely to study the relationships between childhood family circumstances and demographic outcomes in as many countries as possible. However, this was only feasible when compromising between a larger number of national data sets for comparison and a stronger limitation in the childhood indicators of parental SES and family context that could be harmonized from these databases. As a consequence, CONOPP was constrained in modeling social inequality transmission processes from one generation to the next in their entire complexity. In addition, the available data for crossnational comparison comprises data on childhood family structure and circumstances collected retrospectively. To test some of the social mechanisms that I discussed (e.g. value transmission) one needs to have data that is measured prospectively. Both limitations - the relatively narrow set of childhood indicators and their retrospective measurement - may be addressed by future research that may use single country data containing a wider set of prospective measures of childhood circumstances to further advance our understanding of the social mechanisms underlying the reproduction of social inequality.

The CONOPP project convincingly showed that young adults demographic behavior and related outcomes are strongly influenced by parental SES as well as by the experience of a parental divorce. The mechanisms leading to poorer outcomes, however, could also include mediators, such as characteristics associated with parental SES (i.e. personality) or other circumstances of the family home (i.e. family conflict as a moderator).

Finally, the timing of experiencing crucial life events during childhood with potentially detrimental long-term consequences may matter. Including age at parental divorce would be a first step towards better grasping how timing and changes in the family situation, and eventually, economic situation may affect children's future life courses. CONOPP focused on parental divorce as the only measure of growing up in a non-standard family, due to data constraints. However, knowledge on eventual cohabitation experience of parents, the values that parents hold regarding alternative living arrangements and the role of stepfamily members in transmitting preferences and behaviors could shed more light on the role of complex family structures during socialization. 
For sociologists, who genuinely are concerned about social inequality, the story of intergenerational transmission of disadvantage is a pessimistic one. Therefore, one may more closely want to look beyond the general pessimism and study under which circumstances children from adverse childhood contexts fare better. Including personality and other dispositional features like locus of control and optimism in life course models will address the issue of resilience as one complementary mechanism of escaping the trap of low SES origin. In addition, a focus on family characteristics that are beneficial for child development, such as shared values, constructive conflict resolution strategies, and finally the availability of external support systems may also help drawing a more detailed and potentially more optimistic picture on how families of origin shape children's adult life courses.

\section{References}

Atkinson, A.B. 1998. Poverty in Europe. Oxford: Wiley-Blackwell.

Baizán, P., M. Domínguez, and M.J. González. 2014. Couple bargaining or socio-economic status? European Societies 16 (1): 3-27.

Bandura, A. 1977. Social learning theory. Englewood Cliffs: Prentice Hall.

Barber, J.S. 2000. Intergenerational influences on the entry into parenthood: Mothers' preferences for family and nonfamily behavior. Social Forces 79 (1): 319-348.

Baumrind, D. 1967. Child care practices anteceding three patterns of preschool behavior. Genetic Psychology Monographs 75 (1): 42-88.

Becker, G.S. 1964. Human capital: A theoretical and empirical analysis, with special reference to education. Chicago: The University of Chicago Press.

Billari, F.C., N. Hiekel, and A.C. Liefbroer. 2019. The social stratification of choice in the transition to adulthood. European Sociological Review 35 (5): 599-615.

Blossfeld, H., and J. Huinink. 1991. Human capital investments or norms of role transition? How women's schooling and career affect the process of family-formation. American Journal of Sociology 97 (1): 143-168.

Bourdieu, P. 1977. Cultural reproduction and social reproduction. In Power and ideology in education, ed. J. Karabel and A.H. Halsey. Oxford: Oxford University Press.

- 2010. Distinction. A social critique of the judgement of taste. London: Routledge.

Brons, M.D., and J. Härkönen. 2018. Parental education and family dissolution: A cross-national and cohort comparison. Journal of Marriage and Family 80 (2): 426-443.

Brons, M.D., A.C. Liefbroer, and H.B.G. Ganzeboom. 2017. Parental socio-economic status and first union formation: Can European variation be explained by the Second Demographic Transition theory? European Sociological Review 33 (6): 809-822.

Cano, T. 2019. Changes in fathers' and mothers' time with children: Spain, 2002-2010. European Sociological Review 35 (5): 616-636.

Cavalli-Sforza, L.L., and M.W. Feldman. 1981. Cultural transmission and evolution: A quantitative approach. Princeton: Princeton University Press.

Clausen, J.S. 1991. Adolescent competence and the shaping of the life course. American Journal of Sociology 96 (4): 805-842.

Crystal, S., and D. Shea. 1990. Cumulative advantage, cumulative disadvantage, and inequality among elderly people. The Gerontologist 30 (4): 437-443.

Gavac, S., S. Murrar, and M. Brauer. 2017. Group perception and social norms. In Social psychology: How other people influence our thoughts and actions, ed. R.W. Summers, 333-359. Santa Barbara: ABC-CLIO. 
Grusec, J.E., and L. Kuczynski. 1997. Parenting and children's internalization of values: A handbook of contemporary theory. New York: Wiley.

Guryan, J., E. Hurst, and M. Kearney. 2008. Parental education and parental time with children. Journal of Economic Perspectives 22 (3): 23-46.

Hitlin, S., and G.H. Elder. 2006. Agency: An empirical model of an abstract concept. Advances in Life Course Research 11: 33-67.

Hofferth, S.L., and J.F. Sandberg. 2001. How American children spend their time. Journal of Marriage and Family 63 (2): 295-308.

Kallgren, C.A., R.R. Reno, and R.B. Cialdini. 2000. A focus theory of normative conduct: When norms do and do not affect behavior. Personality and Social Psychology Bulletin 26 (8): 1002-1012.

Keijer, M.G., I. Nagel, and A.C. Liefbroer. 2016. Effects of parental cultural and economic status on adolescents' life course preferences. European Sociological Review 32 (5): 607-618.

Khan, S. 2011. Privilege. The making of an adolescent elite at St. Paul's school. Princeton: Princeton University Press.

Kohn, M.L. 1969. Class and conformity: A study in values. Homewood: Dorsey Press.

Koops, J.C., A.C. Liefbroer, and A.H. Gauthier. 2017. The influence of parental educational attainment on the partnership context at first birth in 16 western societies. European Journal of Population 33 (4): 533-557.

. 2020. Explaining cross-national variation of parental educational differences in having a fist birth while cohabiting. In Understanding nonmarital childbearing: the role of socioeconomic background and ethnicity in Europe and North-America, ed. J.C. Koops, 75-103. Groningen: University of Groningen.

Lareau, A. 2003. Unequal childhoods: Class, race, and family life. Berkeley: University of California Press.

Liefbroer, A.C., and F.C. Billari. 2010. Bringing norms back in: A theoretical and empirical discussion of their importance for understanding demographic behaviour. Population, Space and Place 16 (4): 287-305.

Mayer, S.E. 1997. What money can't buy. Family income and children's life chances. Cambridge, MA: Harvard University Press.

McLanahan, S. 2004. Diverging destinies: How children are faring under the second demographic transition. Demography 41 (4): 607-627.

McLanahan, S., and C. Percheski. 2008. Family structure and the reproduction of inequalities. Annual Review of Sociology 34: 257-276.

Mincer, J. 1974. Schooling, experience and earnings. New York: Columbia University Press.

Mooyaart, J.E., and A.C. Liefbroer. 2016. The influence of parental education on timing and type of union formation: Changes over the life course and cver time in the Netherlands. Demography 53 (4): 885-919.

2018. Becoming obese in young adulthood: The role of career-family pathways in the transition to adulthood for men and women. BMC Public Health 19 (1511): 1-12.

Mooyaart, J.E., F.C. Billari, and A.C. Liefbroer. 2019. Born to be rich? The influence of family background and life course pathways on the income trajectories of young adults. In Linkages between family background, family formation and disadvantage in young adulthood, ed. J.E. Mooyaart, 139-2016. Groningen: University of Groningen.

Muller, J.S., N. Hiekel, and A.C. Liefbroer. 2020. The long-term costs of family trajectories: Women's later life earnings across Europe. Demography 57: 1007-1034.

Patterson, G.R., J.B. Reid, and T.J. Dishion. 1992. A social learning approach. Eugene, OR: Castalia.

Ramey, G., and V.A. Ramey. 2009. The rug rat race. Working Paper No. 15284. National Bureau of Economic Research.

Studer, M., A.C. Liefbroer, and J.E. Mooyaart. 2018. Understanding trends in family formation trajectories: An application of Competing Trajectories Analysis (CTA). Advances in Life Course Research 36: 1-12. 
Surkyn, J.J., and R. Lesthaeghe. 2004. Value orientation and the second demographic transition (SDT) in Northern, Western and Southern Europe: An update. Demographic Research 3: 45-86. Tilly, C. 1998. Durable inequality. Berkeley: University of California Press.

Weininger, E.B., A. Lareau, and D. Conley. 2015. What money doesn't buy: Class resources and children's participation in organized extracurricular activities. Social Forces 94 (2): 479-503.

Zoutewelle-Terovan, M., and A.C. Liefbroer. 2018. Swimming against the stream: Non-normative family transitions and loneliness in later life across 12 nations. The Gerontologist 58 (6): 1096-1108.

Open Access This chapter is licensed under the terms of the Creative Commons Attribution 4.0 International License (http://creativecommons.org/licenses/by/4.0/), which permits use, sharing, adaptation, distribution and reproduction in any medium or format, as long as you give appropriate credit to the original author(s) and the source, provide a link to the Creative Commons license and indicate if changes were made.

The images or other third party material in this chapter are included in the chapter's Creative Commons license, unless indicated otherwise in a credit line to the material. If material is not included in the chapter's Creative Commons license and your intended use is not permitted by statutory regulation or exceeds the permitted use, you will need to obtain permission directly from the copyright holder. 